\title{
Instrumentos de rastreamentos de maus-tratos à pessoa idosa na rotina do atendimento clínico odontológico público
}

\author{
Instruments for tracking mistracts to elderly people in the routine of public dental clinic care \\ Instrumentos para el seguimiento de errores a personas mayores en la rutina de la clínica dental pública
}

\begin{abstract}
RESUMO
O estatuto do idoso trouxe mudanças significativas para a legislação brasileira quanto a qualidade de vida de idosos. Mesmo garantida por lei, esta qualidade de vida tem sido alvo de estudos que apontam a resultados alarmantes de maus tratos. Objetivo: evidenciar a importância da aplicabilidade dos instrumentos para rastreamento de maus tratos em idosos pelos cirurgiões-dentistas na identificação de violência sofrida em domicílio na rotina do atendimento clínico dos pacientes cadastrados na Estratégia Saúde da Família (ESF). Método: Trata-se de uma revisão de literatura, que foi realizada no mês de junho de 2019. Resultados: Embora as fontes governamentais não apontem um grande índice, a violência contra o idoso acontece dentro do lar, dificultando sua identificação. Os cirurgiões-dentistas cadastrados na ESF têm fundamental importância no uso de instrumentos para rastreamento de maus tratos, encaminhando os casos aos órgãos de proteção. Conclusão: Quando capacitado, 0 cirurgião dentista pode realizar o rastreamento de maus tratos ao idoso de maneira eficaz e conclusiva através dos instrumentos de rastreamento.
\end{abstract}

DESCRITORES: Maus-Tratos ao Idoso; Estratégia Saúde da Família; Cirurgião-Dentista.

\section{ABSTRACT}

The status of the elderly has brought significant changes to Brazilian legislation regarding the quality of life of the elderly. Although guaranteed by law, this quality of life has been the subject of studies that point to alarming results of mistreatment. Objective: to highlight the importance of the applicability of instruments for tracking abuse in the elderly by dentists in the identification of violence suffered at home in the routine of clinical care for patients registered in the Family Health Strategy (ESF). Method: This is a literature review, which was carried out in June 2019. Results: Although government sources do not indicate a high rate, violence against the elderly occurs within the home, making it difficult to identify. Dental surgeons registered with the FHS are of fundamental importance in the use of instruments for tracking ill-treatment, referring cases to protection agencies. Conclusion: When trained, the dental surgeon can effectively and conclusively track the abuse of the elderly through the screening instruments.

DESCRIPTORS: Mistreatment of the Elderly; Family Health Strategy; Dental surgeon.

\section{RESUMEN}

La situación de las personas mayores ha traído cambios significativos a la legislación brasileña en relación con la calidad de vida de las personas mayores. Aunque garantizada por la ley, esta calidad de vida ha sido objeto de estudios que apuntan a resultados alarmantes del maltrato. Objetivo: resaltar la importancia de la aplicabilidad de los instrumentos de seguimiento del maltrato en el anciano por parte de los odontólogos en la identificación de la violencia sufrida en el hogar en la rutina de la atención clínica de los pacientes registrados en la Estrategia Salud de la Familia (ESF). Método: Se trata de una revisión de la literatura, que se realizó en junio de 2019. Resultados: Si bien fuentes gubernamentales no señalan una tasa alta, la violencia contra las personas mayores ocurre dentro del hogar, lo que dificulta su identificación. Los cirujanos dentistas registrados en la FHS son de fundamental importancia en el uso de instrumentos de seguimiento de malos tratos, remitiendo los casos a las agencias de protección. Conclusión: cuando está capacitado, el cirujano dental puede realizar un seguimiento eficaz y concluyente del abuso de los ancianos a través de los instrumentos de detección.

DESCRIPTORES: Maltrato a los Ancianos; Estrategia de salud familiar; Cirujano dentista.

RECEBIDO EM: 09/09/2020 APROVADO EM: 08/01/2021 


\section{José Itamar de Omena Mateus Rocha}

Graduado em Odontologia pelo Centro Universitário Tiradentes - Maceió-AL(2018). Especialista em Gestão Pública pela Uniasselvi (2020). Pós Graduado em Harmonização Orofacial pelo Instituto Pithon Napoli (SP). Atualmente é Cirurgião-Dentista do Programa Saúde da Família (PSF) do município de São José da Laje (AL). Mestrando Sociedade, Tecnologias e Políticas Públicas pelo Centro Universitário Tiradentes, Maceió-AL. Pós Graduando em Gênero e Sexualidade pela FAVENI.

ORCID: 0000-0003-2397-1742

\section{Ana Lídia Soares Cota}

Graduada em Odontologia pela Universidade Federal de Alagoas -2003, Mestrado em Odontologia pela Universidade Norte do Paraná -2008 e Doutorado em Ciências Odontológicas Aplicadas pela Faculdade de Odontologia de Bauru - USP -2013. Tem experiência na área de Odontologia. Atualmente é cirurgiã- dentista da Secretaria Municipal de Saúde de Maceió, Docente titular do curso de Odontologia, Docente Permanente do Programa de Pós-Graduação (Mestrado/Doutorado) em Sociedade, Tecnologias e Politicas Públicas do Centro Universitário Tiradentes - UNIT/AL.

ORCID: 0000-0001-8220-7846

\section{Wanderson Thales de Souza Braga}

Acadêmico em odontologia no Centro Universitário Tiradentes - UNIT/AL. Atual membro da Liga acadêmica de Diagnóstico por Imagem Odontológica - LADIO/Cesmac (Ciclo 2019-2020). Atual membro do projeto de Extensão Nutricionando - UFAL. ORCID: 0000-0001-8220-7846

\section{Robson Rodrigues da Silva}

Acadêmico do curso de Nutrição pelo Centro Universitário Tiradentes, UNIT-AL, mentor do curso de nutrição do Centro Universitário Tiradentes, membro do Grupo de Estudos em Nutrição em Saúde Pública (GENUSP). Bolsista do programa de Extensão ARTFAL do Instituto Federal de Alagoas.

ORCID: 0000-0002-5438-7920

\section{Laura Morgana Pino dos Santos}

Graduada em Odontologia pelo Centro Universitário Tiradentes - Maceió-AL(2018). Especialista em Prótese Dentária pela São Leopoldo Mandic (2020). Atualmente é servidora pública do estado de Alagoas.

ORCID: 0000-0002-3894-0693

\section{Sabrina de Lima Melo}

Graduada em Odontologia pelo Centro Universitário Tiradentes - Maceió-AL(2018). Especialista em Prótese Dentária (COESP-PB) (2020). Atualmente é Cirurgiã-Dentista do Programa Saúde da Família (PSF) do município de Dois Riachos (AL).

ORCID: 0000-0003-4414-0235

\section{INTRODUÇÃO}

E m 1980, um pouco antes da convocação da Primeira Assembleia Mundial sobre o Envelhecimento, existiam 378 milhões de pessoas no mundo com 60 anos ou mais. Ao longo das últimas três décadas, esse número subiu para 759 milhões ${ }^{1}$.

$\mathrm{O}$ avanço tecnológico, associado às melhorias nas condições sanitárias, fez com que a expectativa de vida dos indivíduos nesses países se prolongasse, trazendo, simultaneamente, com esse benefício, novos problemas com os quais é preciso lidar, como a violência contra aqueles que pertencem à terceira idade ${ }^{2}$.

A Constituição Federal de 1998, no artigo 230, assegurou os direitos da pes- soa idosa e o Estatuto do Idoso (2003) abrangeu, entre outras disposições, os direitos fundamentais do idoso, as medidas de proteção, as políticas de atendimento, o acesso à justiça e o estabelecimento de penas para os crimes mais comuns praticados contra a pessoa idosa. Entretanto, esses dispositivos legais não foram eficientes para solucionar os problemas da violência ${ }^{3}$.

As formas de violência contra idosos mais comuns são o abuso físico, o abuso sexual, o abuso emocional ou psicológico, a exploração financeira ou material, o abandono e a negligência. Elas podem ocorrer isolada ou conjuntamente $e^{4}$.

Uma das maiores dificuldades no combate à violência contra o idoso é a subnotificação do fenômeno, sobretudo quando praticado no âmbito doméstico. Isso ocorre porque a violência doméstica costuma ser tratada como assunto privado pela família e porque a vítima, geralmente, mantém um vínculo de dependência com o seu agressor, temendo denunciá-lo5.

É importante destacar que a violência contra o idoso permeia a vida de forma oculta e silenciosa e os profissionais de saúde podem quebrar este silêncio, de modo a auxiliar na minimização dos danos gerados em cada família e interromper a continuidade desse ciclo. Portanto, os serviços de saúde são uma das principais portas de reconhecimento das vítimas de violência intrafamiliar contra o idoso ${ }^{6}$.

Instrumentos vêm sendo elaborados e revisados nos últimos 30 anos, desde protocolos criados por serviços assistenciais 


\section{artigo}

Rocha, J.I.O.M.; Cota, A.L.S.; Braga, W.T.S.; Rodrigues da Silva, R.; Santos, L.M.P.; Melo, S.L.

Instrumentos de rastreamentos de maus-tratos à pessoa idosa na rotina do atendimento clínico odontológico público

e de saúde, baseados no conhecimento prático de seus profissionais, muitas vezes sem validação científica; até instrumentos de rastreio construídos dentro das normas acadêmicas de pesquisa ${ }^{7}$.

Este artigo tem por objetivo evidenciar a importância da aplicabilidade dos instrumentos para rastreamento de maus tratos em idosos pelos cirurgiões-dentistas na identificação de violência sofrida em domicílio na rotina do atendimento clínico dos pacientes cadastrados na ESF.

\section{MÉTODOS}

O presente artigo trata-se de uma revisão literatura, que caracteriza-se por uma pesquisa que busca a análise referente ao estudo definido, por meio da busca de dados relevantes encontrados na literatura fornecendo informações que poderá ser analisada e posteriormente discutida para se chegar a um objetivo específico.

A sua construção deu-se a partir das seguintes etapas: 1) Identificação da problemática; 2) Formulação da pergunta norteadora; 3) Definição dos objetivos; 4) Estabelecimento dos critérios de inclusão e exclusão; 5) Busca de artigos por meio das bases de dados; 6) Leitura dos artigos encontrados nas bases de dados; 7) Análise dos resultados; 8) Apresentação da revisão.

Para responder a seguinte questão: Como o instrumento de rastreamento auxilia o cirurgião-dentista no enfrentamento da violência doméstica sofrida pelo idoso? Foi realizado o levantamento dos artigos selecionados por meio das bases de dados: Scientific Eletronic Library Online (SciELO), National Library of Medicine (PubMed) e Google Acadêmico a partir dos descritores: "Maus-Tratos ao Idoso", "Serviços de Saúde para Idosos" e "Profissionais da Saúde", que foram consultados e validados nos Descritores em Ciências da Saúde (DeCS/MeSH) subsidiados pelo operador booleano "and".

A coleta de dados foi realizada em junho de 2019, e teve como critérios de inclusão artigos publicados no período de 2002 a 2014, disponíveis gratuitamente na íntegra, publicados em português, espanhol e inglês, artigos que abordem sobre a temática e respondam à pergunta norteadora. E como critérios de exclusão foram as produções científicas em formato de teses, resumos expandidos e artigos em duplicata.

Para a seleção dos manuscritos, os pesquisadores selecionaram os artigos de acordo com o título. O resumo foi então usado para avaliar os critérios de inclusão e, em seguida, a avaliação da publicação do texto completo confirmou esses critérios, sendo extraído os dados. As divergências, que ocorreram 2 vezes, foram resolvidas por consenso. Os artigos resultantes foram revisados manualmente com o objetivo de identificar estudos que atendessem aos critérios de inclusão descritos acima.

Para a análise dos dados, foi elaborada uma planilha no programa Microsoft Excel 2019, com as seguintes variáreis: título do artigo, ano de publicação, tipo de estudo e principais resultados. Realizada a análise bibliométrica, na sequência foram analisados os achados, os quais foram agrupados por semelhança e organizados em categorias temáticas, resultando na apresentação da revisão/síntese do conhecimento.

Os dados foram obtidos através da coleta de dados bibliográficos e não teve participantes envolvidos, portanto não houve necessidade de submissão do trabalho ao Comitê de Ética em Pesquisa (CEP), pois se tratou de uma pesquisa que utilizou informações de domínio público.

\section{RESULTADOS}

$\mathrm{Na}$ busca para a realização do presente estudo, foram encontrados 2.507 artigos nas bases de dados: SciELO, PubMed e Google Acadêmico. Foram excluídos 2.294 artigos por estarem fora do recorte temporal, 112 publicações foram excluídas após leitura do título e 89 após leitura do resumo, resultando em 12 artigos que possuíam relevância para esta revisão (Figura 1).

No Quadro 1 estão caracterizados os artigos que irão compor esta revisão.

\section{DISCUSSÃO}

O envelhecimento pode ser compreendido como um processo natural de perdas ou redução da capacidade funcional do ser humano que ocorre com o passar dos anos ${ }^{8}$. $\mathrm{O}$ aumento quantitativo da população corresponde a 17,6 milhões de idosos no Brasil e estima-se que o país alcançará em 2020 o $6^{\circ}$ lugar, no ranking mundial, com o maior número de indivíduos nesta faixa etária. Já em Alagoas em 2010, de um total de 3.120.494 habitantes, 276.170 apresentavam 60 anos ou mais de idade, o que significa $8,85 \%$ da população alagoana. Em Maceió, de um total de 932.748 habitantes, 79.087 são maiores de 60 anos, o que repre-

\section{Figura 1 - Fluxograma de seleção dos artigos elegiveis.}

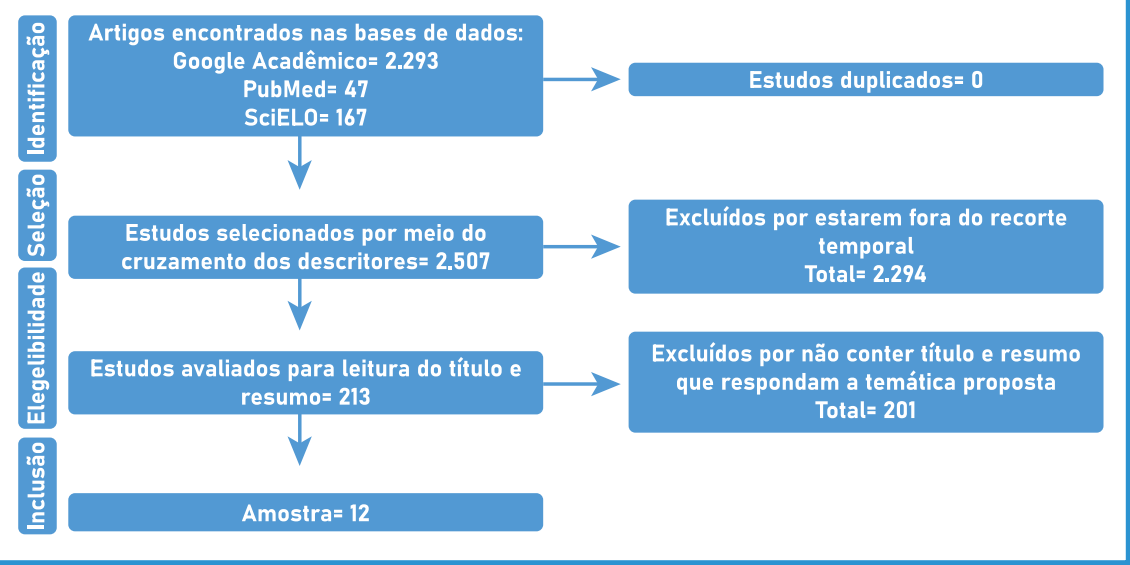

Fonte: Autores, 2019. 
Quadro 1: Caracterização dos artigos elencados.

\begin{tabular}{|c|c|c|c|c|}
\hline N & TÍTULO & ANO & TIPO DE ESTUDO & RESULTADOS \\
\hline 7 & $\begin{array}{c}\text { Rastreamento de violência contra } \\
\text { pessoas idosas cadastradas pela } \\
\text { Estratégia de Saúde da Familia em } \\
\text { João Pessoa-PB }\end{array}$ & 2014 & $\begin{array}{l}\text { Estudo transversal, } \\
\text { prospectivo }\end{array}$ & $\begin{array}{c}\text { A prevalência do risco de violência foi de } 54,7 \% \text { e da vio- } \\
\text { lência de fato acontecida foi de } 35,4 \% \text {. O rastreamento do } \\
\text { risco e da violência contra a pessoa idosa é uma ação pos- } \\
\text { sível de ser realizada no ambiente de prática da atenç̧ão } \\
\text { básica e pode oferecer parâmetros para a identificação } \\
\text { precoce da situação de risco, antecipando intervenções e } \\
\text { prevenindo agravos. }\end{array}$ \\
\hline 8 & $\begin{array}{c}\text { Financial Exploitation and } \\
\text { Psychological Mistreatment Among } \\
\text { Older Adults: differences between } \\
\text { African Americans and non-African } \\
\text { Americans in a population-based } \\
\text { survey }\end{array}$ & 2010 & $\begin{array}{l}\text { Estudo quanti- } \\
\text { qualitativo }\end{array}$ & $\begin{array}{l}\text { As taxas de prevalência foram significativamente maiores } \\
\text { para afro-americanos do que para não-afro-americanos } \\
\text { devido à exploração financeira desde os } 60 \text { anos ( } 23,0 \% \text { vs. } \\
\text { 8,4\%) e nos últimos } 6 \text { meses ( } 12,9 \% \text { vs. } 2,4 \% \text { ) e para maus- } \\
\text { tratos psicológicos desde a transformação } 60 \text { ( } 24,4 \% \text { vs. } \\
13,2 \% \text { ) e nos últimos } 6 \text { meses }(16,1 \% \text { vs. } 7,2 \%)\end{array}$ \\
\hline 10 & $\begin{array}{l}\text { A construção da violência contra } \\
\text { idosos }\end{array}$ & 2007 & Revisão da literatura & $\begin{array}{c}\text { O estudo revelou que a violência contra o idoso é alarmante } \\
\text { e ocorre na grande maioria das vezes no âmbito familiar. } \\
\text { Essa violência é um fenômeno complexo multifacetado e } \\
\text { dinâmico de difícil controle, até mesmo em países com alto } \\
\text { nível de qualidade de vida. }\end{array}$ \\
\hline 12 & $\begin{array}{l}\text { Ocorrência de maus-tratos em ido- } \\
\text { sos no domicílio }\end{array}$ & 2004 & Estudo qualitativo & $\begin{array}{l}\text { Os maus-tratos no domicilio ocorreram com maior frequ- } \\
\text { ência entre idosos do sexo masculino }(58,6 \%) \text {, com Idade } \\
\text { media de } 75 \text { anos. Da amostra analisada, }(45,2 \%) \text { eram ca- } \\
\text { sados e foram agredidos por familiares como filhos, netos, } \\
\text { genros e noras }(47,1 \%) \text {. A maioria }(57,4 \%) \text { dos idosos não } \\
\text { recorreu ao atendimento medico e serviços de saúde. Do } \\
\text { total, apenas }(9,2 \%) \text { foram encaminhados para o hospital. }\end{array}$ \\
\hline 15 & $\begin{array}{c}\text { Características dos idosos vítimas } \\
\text { de violência doméstica no Distrito } \\
\text { Federal }\end{array}$ & 2012 & $\begin{array}{l}\text { Estudo descritivo e } \\
\text { exploratório }\end{array}$ & $\begin{array}{l}\text { Evidenciou-se aumento do número de denúncias a partir } \\
\text { de } 2003 \text {, mais expressivas no sexo masculino. Os casados } \\
\text { são os mais agredidos. Quanto aos agressores, } 62,81 \% \\
\text { não têm parentesco com a vítima e } 13,56 \% \text { das agressões } \\
\text { foram cometidas por filho. Os resultados evidenciaram a } \\
\text { situação de vulnerabilidade deste grupo e a importância } \\
\text { dos serviços públicos voltados para a proteção do idoso. }\end{array}$ \\
\hline 16 & $\begin{array}{l}\text { O reconhecimento pela equipe da es- } \\
\text { tratégia saúde da familia da violência } \\
\text { intrafamiliar contra idosos }\end{array}$ & 2008 & Estudo quantitativo & $\begin{array}{l}\text { Constatou-se nesta pesquisa que } 91 \% \text { (87) dos integrantes } \\
\text { da ESF percebem a violência intrafamiliar contra os idosos } \\
\text { na cidade de Curitiba, principalmente casos de abandono/ } \\
\text { negligência, de acordo com } 25 \% \text { (75) das respostas dos } \\
\text { entrevistados. Os fatores de risco mais comuns relaciona- } \\
\text { dos aos maus-tratos referem-se à familia totalizando } 33 \% \\
\text { (229) das respostas. }\end{array}$ \\
\hline 17 & $\begin{array}{l}\text { The process of validation of a three- } \\
\text {-dimensional model for the identifi- } \\
\text { cation of abuse in older adults }\end{array}$ & 2013 & Estudo qualitativo & $\begin{array}{l}\text { Mostraram que os indicadores de risco aumentaram signi- } \\
\text { ficativamente a probabilidade de abuso em indivíduos que } \\
\text { vivem na comunidade e em instituições de longa perma- } \\
\text { nência. As três dimensões de identificaçãa de abuso foram } \\
\text { parcialmente sobrepostas na identificação de diferentes } \\
\text { taxas de abuso. }\end{array}$ \\
\hline 20 & $\begin{array}{l}\text { O cirurgião-dentista frente à violên- } \\
\text { cia doméstica: conhecimento dos } \\
\text { profissionais em âmbito público e } \\
\text { privado }\end{array}$ & 2013 & $\begin{array}{l}\text { Estudo descritivo, } \\
\text { qualitativo }\end{array}$ & $\begin{array}{l}\text { Não houve diferença estatisticamente significante entre as } \\
\text { repostas fornecidas pelos grupos de profissionais estuda- } \\
\text { dos. Verificou-se um baixo percentual de cirurgiões-dentis- } \\
\text { tas que realizaram atendimento em crianças, mulheres e } \\
\text { idosos vítimas de violência domemstica. }\end{array}$ \\
\hline
\end{tabular}




\section{artigo}

Rocha, J.I.O.M.; Cota, A.L.S.; Braga, W.T.S.; Rodrigues da Silva, R.; Santos, L.M.P.; Melo, S.L.

Instrumentos de rastreamentos de maus-tratos à pessoa idosa na rotina do atendimento clínico odontológico público

\begin{tabular}{|c|c|c|c|c|}
\hline 21 & $\begin{array}{c}\text { Violência contra a pessoa idosa: } \\
\text { análise das notificações realizadas } \\
\text { no setor saúde - Brasil }\end{array}$ & 2010 & $\begin{array}{l}\text { Estudo descritivo, } \\
\text { retrospectivo }\end{array}$ & $\begin{array}{l}\text { A violência física foi significativamente mais frequente } \\
\text { no sexo masculino, no grupo com } 60 \text { a } 69 \text { anos, fora do } \\
\text { domicílio, praticada por agressores que não eram filhos, } \\
\text { com suspeita de ingestão de bebida alcoólica. A violência } \\
\text { psicológica foi mais frequente entre idosas, no domicilio, } \\
\text { infligida pelos filhos, com suspeita de uso de bebida alcoóli- } \\
\text { ca e de maneira crônica. A violência sexual foi mais comum } \\
\text { no sexo feminino, por agressores que não eram filhos, mas } \\
\text { que consumiram bebida alcoólica. }\end{array}$ \\
\hline 22 & $\begin{array}{l}\text { Discussing screening for elder abuse } \\
\text { at primary health care level }\end{array}$ & 2008 & Revisão da literatura & $\begin{array}{l}\text { Os profissionais da saúde possuem um papel importante } \\
\text { na identificaçãa, gerenciamento e prevenção da ocorrência } \\
\text { de violência ao idoso, mantendo uma relação de confiança } \\
\text { com os pacientes e seus cuidadores. Esta revisão argu- } \\
\text { menta que ao implementar a rotina prática de triagem } \\
\text { e trabalhando conscientemente com outros serviços na } \\
\text { comunidade, o abuso contra o idoso pode ser evitado ou, } \\
\text { pelo menos, gerenciado de forma adequada. }\end{array}$ \\
\hline 23 & $\begin{array}{l}\text { Uma revisão sobre instrumentos de } \\
\text { rastreamento de violência doméstica } \\
\text { contra o idoso }\end{array}$ & 2006 & Revisão sistemática & $\begin{array}{c}\text { Dos dezessete instrumentos encontrados, somente a } \\
\text { Conflicts Tactics Scale foi adaptada para o Brasil, ainda que } \\
\text { para uso em um grupo etário mais jovem. Ainda assim, } \\
\text { de forma geral, há lacunas importantes nos processos de } \\
\text { concepção, validação e adaptação desses instrumentos no } \\
\text { Brasil e no exterior }\end{array}$ \\
\hline 24 & $\begin{array}{l}\text { Reassessing the construct validity of } \\
\text { a Brazilian version of the instrument } \\
\text { Caregiver Abuse Screen (CASE) used } \\
\text { to identify risk of domestic violence } \\
\text { against the elderly }\end{array}$ & 2009 & Estudo transversal & $\begin{array}{l}\text { Usando as correlações Tau-b de Kendall, o CASE foi positi- } \\
\text { vamente associado a dois outros instrumentos que avaliam } \\
\text { DVAE (H / S-EAST: sobrecarga do cuidador e depressão. }\end{array}$ \\
\hline
\end{tabular}

senta $8,5 \%$ do total de habitantes .

No entanto, esse aumento da população idosa também gera aspectos negativos, como aumento da violência e maus-tratos. A Organização Mundial de Saúde (OMS) define maus-tratos na terceira idade como ato único ou repetido, ou ainda, como ausência de ação apropriada que cause dano, sofrimento ou angústia, e que ocorra dentro de um relacionamento de confiança. Esse cenário é atualmente uma preocupação relacionada com a saúde pública e a violação dos direitos humanos e, por não ter um fator unicausal, trata-se de um fenômeno biopsicossocial ${ }^{10}$.

Mas para que o idoso possa desfrutar de uma vida digna e ter qualidade de vida é importante que as políticas que estão em vigor através da legislação correlata sejam cumpridas. No Brasil já existe uma legislação que garante a proteção de uma vida digna para o idoso como, por exemplo, a Lei 8.842/94 da Política Nacional do Idoso
(PNI), que em seu artigo primeiro assegura "os direitos sociais do idoso, criando condições para promover sua autonomia, integração e participação efetiva na sociedade ${ }^{11}$.

É importante salientar que muitas são as dificuldades enfrentadas pela idade avançada, que afetam não só os aspectos físicos decorrentes da fragilidade e vulnerabilidade própria do estado fisiológico, mas também novos agravos vivenciados pelos idosos na sociedade contemporânea, em potencial, a crescente violência social contra eles ${ }^{12}$.

A dependência, seja ela de qualquer um ou de ambos os lados (pessoa idosa x família), é um fator que aumenta o risco de violência. A dependência econômica de filhos adultos em relação a pais idosos é muito aparente no Brasil, e consiste em fator de risco, especialmente quando a pessoa idosa é a única fonte de recursos da família. A dependência da pessoa idosa em relação à sua família aumenta a proximidade, o que pode resultar em aspectos positivos ou negativos na relação. Se a dependência for causada por adoecimento, as chances de aumento de estresse, cansaço físico e emocional, e sobrecarga sobre a família (principalmente sobre o cuidador) se elevam, e complicam a relação ${ }^{10}$.

A escassez de informação quanto aos agredidos e agressores é uma temática delicada, de difícil estudo, principalmente porque os idosos, de um modo geral, não denunciam abusos e agressões sofridas em função do constrangimento e do medo de repressão por parte de seus cuidadores que são, frequentemente, os próprios agressores ${ }^{13}$.

A associação da violência contra a pessoa idosa com sintomas depressivos e de déficit cognitivo já foi relatada na literatura acadêmica, porém, cada população possui um perfil demográfico e conjuntura social distintas, que fazem com que investigaçôes locais sejam necessárias?

Durante muito tempo os diversos atos 
de violência contra as pessoas idosas foram tidos como problemas particulares de cada família, embaçados por contextos culturais, não sendo captada sua relevância por olhares profissionais e nem cabendo, portanto, qualquer intervenção por parte do Estado7.

Autores como Minayo (2003) e Menezes (1999), foram os pioneiros na construção de literatura que tratavam da violência contra idosos no Brasil, e após esse fato é que a preocupação com a qualidade de vida dos idosos entrou na agenda de saúde pública brasileira. Ou seja, esse assunto só ganhou mais repercussão e preocupação por parte das autoridades há menos de duas décadas.

As atuais fontes de dados governamentais disponíveis sobre o tema permitem retratar a questão da violência contra a pessoa idosa a partir de uma perspectiva apenas clínico-biológica, negligenciando-se a violência que ocorre dentro do lar. Os dados são mais voltados para as necessidades físicas decorrentes de quedas, acidentes de trânsito (atropelamentos, quedas por transporte inadequado), homicídios (sem diferenças de proporção em relação à população em geral), suicídios (mais significativo nesse grupo em relação à média da população). Porém esses dados são pouco consistentes no Brasil, fato observado também na literatura internacional, que ressalta elevada subnotificação em termos mundiais, com estimativas que descrevem que $70 \%$ das lesões e traumas sofridos pelos idosos não compõem as estatísticas reais ${ }^{13}$.

A Coordenação de Desenvolvimento de Programas e Políticas de Saúde (CODEPPS) destaca alguns fatores de risco que podem predispor uma pessoa a agredir um idoso, como o isolamento social, dependência (física, psíquica e emocional), dificuldades financeiras, altos níveis de estresse por parte do cuidador, entre outros ${ }^{14}$.

A aceitação do acontecimento da violência como sendo natural das relações entre os membros de uma família é o fenômeno que alguns autores chamam de familism, comum entre os latinos, onde se enfatizam as necessidades da família acima das necessidades individuais, através do qual a pessoa idosa acaba aceitando o mau tratamento que lhe é dispensado e evita relatar os abusos, na intenção de preservar a família ${ }^{15}$.

Em âmbito social, a violência contra o idoso não ocupa tanto destaque como a provocada em crianças e mulheres, mas age de forma silenciosa dentro das relações humanas de uma comunidade. Existem poucos estudos a respeito dessa temática, principalmente a que envolve a família. Apesar de existir políticas que foram construídas para o combate da violência, ainda há muito que investir sobre a situação de agressão à pessoa com maior idade ${ }^{16}$.

A identificação das pessoas idosas vítimas de violência ou em risco de, junto com a inicialização das intervenções, podem, em muitos casos, ser alcançadas em cenários de prática de serviços de saúde. Muitos profissionais de saúde não questionam seus pacientes sobre um possível abuso ${ }^{17}$.

Eles não estão a par dos sinais de violência contra a pessoa idosa e alegam não possuírem ferramentas adequadas para essa identificação. Atribuem o não aprofundamento na questão devido à sua já excessiva carga de trabalho, falta de tempo durante os atendimentos, mas também apontam lacunas em suas formações ou ausência de treinamento durante o exercício profissional, acerca do reconhecimento dos sinais da violência contra a pessoa idosa. $\mathrm{O}$ abuso só é detectado pelos profissionais de saúde através da apresentação de sinais óbvios de violência ${ }^{15}$.

Os profissionais de saúde têm aumentado sua preocupação com essa questão, mas os números sobre sua identificação e sobre os casos denunciados ainda permanecem baixos. A melhoria na detecção da violência sofrida deveria ser uma meta de alta prioridade para os serviços assistenciais e de saúde e o seu rastreio acontecer de forma contínua, tornando-se parte integrante e permanente das ações ali oferecidas à clientela idosa ${ }^{17}$.

Contudo, temem notificar situações suspeitas de maus-tratos por medo de perder os pacientes, falta de confiança no serviço de proteção, incerteza do diagnóstico e desconhecimento da verdadeira res- ponsabilidade em notificar. Alguns profissionais acreditam, ainda, que o sistema judiciário nada fará em relação ao caso e, portanto, a comunicação às autoridades competentes não traria nenhum resultado positivo $^{18}$.

Em geral, fora do ambiente de emergência, a equipe de saúde se depara mais frequentemente com formas sutis de violência nas quais a negligência e/ou o abuso psicológico predominam. A identificação dessas apresentações mais insidiosas de abuso é dificultada pela presença concomitante de doenças crônicas em idosos, cujas manifestações podem mimetizar atos violentos ou diminuir a suspeição clínica dos mesmos ${ }^{19}$.

Uma pesquisa feita no município de Guaratinguetá-SP, avaliando o conhecimento do Cirurgião-Dentista frente à violência doméstica, mostra o baixo percentual de profissionais de Odontologia da rede pública assim como da rede privada que já atenderam e/ou suspeitaram de crianças, mulheres e idosos que foram vítimas da violência doméstica, durante sua atuação profissional. O estudo apontou uma menor identificação pelos Cirurgiôes-Dentistas de violência doméstica a idosos na rede pública $(5,0 \%)$, assim como na rede privada $(0,05)$ e verificou à atitude frente à identificação ou suspeita de violência doméstica e pode-se observar, que boa parte dos profissionais comunicariam as autoridades competentes caso confirmassem casos de violência doméstica contra idosos (60\% dos cirurgiões da rede pública e $70 \%$ da rede privada $)^{20}$.

A investigação sistemática da violência contra a pessoa idosa feita por todos os profissionais que lhes prestam serviço, através de um instrumento específico e eficaz, pode facilitar o reconhecimento da violência ou do risco de sofrê-la, ajudando a desvendar um número maior de vítimas, que poderão então sair de tal sofrimento. Mesmo este rastreamento não identificaria a totalidade dos casos, porém cada caso identificado, que de outra forma estaria oculto, é importante ${ }^{17}$.

Dados do Sistema de Informação de Agravos de Notificação, responsável pelo 
processamento de todas as fichas de notificação compulsória de violência contra a pessoa idosa no Brasil, contabilizaram, no ano de 2010, 3.593 casos de violência contra a pessoa idosa notificados por profissionais de saúde, oriundos de $524 \mathrm{mu}$ nicípios brasileiros. Tais dados evidenciam a expressiva subnotificação da violência entre a população idosa no país, haja vista as dimensões continentais do mesmo e os relatos diários na mídia, sobre a ocorrência de $\operatorname{casos}^{21}$.

Por muitos anos, associações profissionais têm recomendado rotinas de rastreamento e adoção de protocolos padronizados para a identificação e intervenção em violência familiar. No entanto, enquanto o rastreamento em cenários pediátricos é largamente aceitável, prática equivalente focando na população idosa não tem sido adotada e nunca foi propriamente consi$\operatorname{derada}^{22}$.

Há consenso de que instrumentos apropriados de rastreamento de violência contra a pessoa idosa sejam cruciais para o progresso da prática e da pesquisa dentro do tema. Ao mesmo tempo, sabe-se que não existem instrumentos universalmente aceitos para a triagem ou identificação da violência doméstica na população de pessoas idosas ${ }^{23}$.

O Hawlek-Sengstock Elder Abuse Screening Test (H-S/EAST) foi criado em 1986, nos Estados Unidos, é um instrumento fácil de ser administrado e de rápida execução que avalia violência física, psicológica, financeira e negligência. Ele não avalia as demais dimensões da violência contra a pessoa idosa, reconhecidas pelo Ministério da Saúde no Brasil, tais como autonegligência, abandono e violência sexual. O H-S/EAST avalia a violência instalada ou presumida a partir da perspectiva da própria pessoa idosa, através de 14 itens de perguntas a serem feitas diretamente a elas, por profissionais que podem ser pouco experientes no tema, na forma de entrevistas ou questionários. Trata-se da mais recente e mais conhecida ferramenta para esta finalidade ${ }^{24}$.

Indicado para avaliar possíveis situações de violência contra pessoas idosas, foi adotado pelo Ministério da Saúde nos cadernos de Atenção Básica. Nele investiga-se a violência física, psicológica, abuso financeiro e econômico. Trata-se de um instrumento de autoavaliação onde a pessoa idosa responderá se sofreu ou não recentemente alguma forma de violência, sendo as perguntas elaboradas de forma indireta. Uma resposta positiva a qualquer um dos itens caracteriza presença de violência contra a pessoa idosa e este foi o parâmetro adotado para o presente estudo ${ }^{7}$.

\section{O H-S/EAST avalia} a violência instalada ou presumida a partir da perspectiva da própria pessoa idosa, através de 14 itens de

perguntas a serem

feitas diretamente a elas, por profissionais que podem ser pouco experientes no tema, na forma de entrevistas ou questionários. Trata-se da mais recente e mais conhecida ferramenta para esta finalidade
O Estatuto do Idoso em seu artigo $9^{\circ}$ estabelece a obrigatoriedade do Estado garantir à pessoa idosa a proteção à vida $\mathrm{e}$ à saúde, mediante efetivação de políticas sociais públicas que permitam um envelhecimento saudável e em condições de dignidade. Já no artigo $10^{\circ}$, cita o dever de todos zelarem pela dignidade do idoso, colocando-o a salvo de qualquer tratamento desumano, violento, aterrorizante, vexatório ou constrangedor, e, no artigo $19^{\circ} \mathrm{em}$ casos de suspeita ou confirmação de maus-tratos serão obrigatoriamente comunicados pelos profissionais de saúde a quaisquer dos seguintes órgãos: autoridade policial, Ministério Público, Conselho Municipal do Idoso; Conselho Estadual do Idoso e Conselho Nacional do Idoso ${ }^{25}$.

Percebe-se que a violência contra a pessoa idosa é um fenômeno que ainda carece ser estudado sob vários aspectos. $\mathrm{O}$ debate franco com a sociedade acerca do tema, a prevenção do abuso, a identificação e encaminhamento correto dos casos, são pontos vitais para que o respeito às vítimas seja reinstalado, a fim de que possam viver seu envelhecimento de forma tranquila, gozando plenamente de suas capacidades físicas e mentais ainda preservadas, sem temor, opressão ou tristeza. Para tanto, é preciso que tal temática seja levada à discussão por diferentes segmentos da sociedade (escolas, igrejas, família, políticos), incluindo as próprias pessoas idosas. Conseguir identificar adequadamente quando uma pessoa idosa está sendo submetida a situações de maus-tratos e/ou negligência é importante na manutenção da sua saúde e na prevenção de agravos?.

\section{CONCLUSÃO}

Com o aumento populacional do idoso, além dos benefícios trazidos, uma série de agravantes simultaneamente o acompanhou, dificultando assim, a realidade de vida destes. Sendo um tema discutido em diversas esferas da sociedade, a violência ainda é subnotificada ou pouco relatada quando é avaliada referente à qualidade de vida do indivíduo maior de 60 anos.

As políticas públicas que assegurem a 
integridade física e moral dos idosos estão disponíveis para consulta nos diversos veículos de comunicação do Governo Federal, porém seu acesso advindo destes ainda é uma realidade difícil, seja pela falta de informação, ou mesmo, pela falta de comprometimento e desejo de ocultação dos seus responsáveis, cabendo ao profissional em saúde ter o conhecimento das ferramentas que asseguram a integridade física e moral dos seus pacientes. A ESF tem um papel fundamental neste cenário, os profissionais precisam capacitar-se para estarem atentos quanto à percepção aos sinais de descaso, maus tratos e violência que acometem os idosos, a fim tomar as providências necessárias, como exemplo encaminhar aos órgãos competentes.
Os testes: $\mathrm{H}-\mathrm{S} / \mathrm{EAST}$ e o Instrumento de Avaliação de Violência e Maus-Tratos Contra a Pessoa Idosa se tornam eficazes quanto ao rastreamento de maus tratos às pessoas idosas, possibilitando ao profissional capacitado realizar os testes de maneira segura, conclusiva e eficaz, permitindo assim uma maior qualidade de vida ao paciente idoso. -

\section{REFERÊNCIAS}

1. United Nations. Department of Economic and Social Affairs. Current Status of the Social Situations, Well-Being, Participation in Development and Rights of Older Persons Worldwide. New York, 2011

2. World Health Organization (WHO) Missing voices: views of older persons on elder abuse. Geneva: World Health Organization, 2002. $24 \mathrm{p}$.

3. Sanches APRA. Violência doméstica contra idosos no município de São Paulo: estudo SABE 2000. 2006. Dissertação (Mestrado em Saúde Pública) - Faculdade de Saúde Pública, Universidade de São Paulo, São Paulo. 2006.

4. Souza JAV, Freitas MC, Queiroz TA. Violência contra os idosos: análise documental. Revista Brasileira de Enfermagem, v. 60, n. 3, p. 268-272, 2007. Disponivel em: http://www.scielo.br/scielo. php?pid=S0034--71672007000300004\&script=sci_arttext. Acesso em: 15 jun 2019.

5. Gondim RMF, Costa LM. Violência contra o idoso. In: Falcão, D.V.S.; DIAS, C. M. S. B. (orgs.). Maturidade e velhice: Pesquisa e intervenções psicológicas. Vol. 1, p. 169-191. São Paulo: Casa do Psicólogo, 2006.

6. Lopes MJM, Paixão DY. Saúde da Familia: história, práticas e caminhos. Porto Alegre: UFRGS, 2007.

7. Florencio, MVL. Rastreamento de violência contra pessoas idosas cadastradas pela Estratégia de Saúde da Familia em João Pessoa-PB. 2014. 124f. Tese (Doutorado em Gerontologia Biomédica) - Pontifícia Universidade Católica do Rio Grande do Sul, Porto Alegre, 2014.

8. Beach SR, Schulz R, Castle NG, Rosen J. Financial Exploitation and Psychological Mistreatment Among Older Adults: differences between africanamericans and non-africanamericans in a population-based survey. Gerontologist. 2010 Dec; 50(6):744-57.

9. IBGE - Instituto Brasileiro de Geografia e Estatística. Síntese de indicadores sociais, 2010. Disponível em: http://www.ibge.gov.br/ home/presidencia/ noticias Acesso em: 15 jun 2019.

10. Santos ACPO, Silva CA, Carvalho LS, Menezes MR. A construção da violência contra idosos. Rev Bras Geriatr. Gerontol. 2007;10(1):1-4.

11. Da Silva CM, Cerri P, Ferreira SMD, Magrini V. Ações Públicas Voltadas para Qualidade de Vida do Idoso. In. Políticas públicas, qualidade de vida e atividade física/ Organizadores: Gustavo Luís Gutierrez, Roberto Vilarta, Roberto Teixeira Mendes. Campinas: Ipes, 2011.

12. Gaioli CL. O. Ocorrência de maus-tratos em idosos no domicilio. Ribeirão Preto. 92 f. Dissertação (Mestrado em Enfermagem), Universidade de São Paulo: 2004.
13. Minayo MCS. A difícil e lenta entrada da violência na agenda do setor saúde. Cadernos de Saúde Pública 2004 maio/junho; 20(3): 646-7.

14. Karsch UM. Idosos dependentes: familias e cuidadores. Cadernos de Saúde Pública, v. 19, n. 3, p. 861-866, 2003.

15. Oliveira MLC, Gomes ACG, Amaral CPM, Santos LBD. Características dos idosos vítimas de violência doméstica no Distrito Federal. Rev. bras. geriatr. Gerontol. 2012 Sep;15( 3): 555-566.

16. Shimbo AY. O reconhecimento pela equipe da estratégia saúde da familia da violência intrafamiliar contra idosos. 2008. 80 f. Dissertação (Mestrado em Enfermagem) - Setor de Ciências da Saúde, Universidade Federal do Paraná, Curitiba, 2008.

17. Cohen $\mathrm{M}$. The process of validation of a three-dimensional model for the identification of abuse in older adults. Arch Gerontol Geriatr. 2013 Nov-Dec; 57(3):243-9.

18. Cavalcanti AL, Valença AMG, Duarte RC. A odontopediatra diante de maus tratos infantis: diagnóstico e conduta. J Bras Odontopediatr Odontol Bebê 2000; 3:451-5.

19. Lachs MS, Pillemer K. Current concepts: abuse and neglect of elderly persons. N Engl J Med 1995; 332:437-43.

20. Carvalho LMF, Galo R, Da Silva RHA. O cirurgião-dentista frente à violência doméstica: conhecimento dos profissionais em âmbito público e privado. Medicina (Ribeirão Preto) 2013; 46(3): 297-304

21. Mascarenhas MMD, Andrade SSCA, Neves ACM, Pedrosa AAG, Silva MMA, Malta DC. Violência contra a pessoa idosa: análise das notificações realizadas no setor saúde - Brasil, 2010. Ciênc Saúde Colet. 2012; 17(9):2331-41.

22. Perel-Levin S. Discussing screening for elder abuse at primary health care level. Switzerland: WHO, 2008.

23. Paixão CM Jr, Reichenheim ME. Uma revisão sobre instrumentos de rastreamento de violência doméstica contra o idoso. Cad. Saúde Pública. 2006 June; 22(6):1137-1149.

24. Reichenheim ME, Paixão CM Jr, Moraes CL. Reassessing the construct validity of a Brazilian version of the instrument Caregiver Abuse Screen (CASE) used to identify risk of domestic violence against the elderly. J EpidemiolCommunity Health. 2009 Nov; 63(11):878-83.

25. Brasil. Casa Civil - Subchefia para Assuntos Jurídicos. Estatuto do Idoso. Lei n. 10.741, de 01 out. de 2003. Disponível em:<http://www. mj.gov.org/sal/codigo_civil/indice.htm>. Acesso em: 15 jun 2019. 